\title{
Halomonas sp. nov., an EPA-Producing Mesophilic Marine Isolate from the Indian Ocean
}

\author{
DIPTI SALUNKHE ${ }^{1}$, NEHA TIWARI $^{1}$, SANDEEP WALUJKAR $^{2}$ and RAMA BHADEKAR ${ }^{1 *}$ \\ ${ }^{1}$ Department of Microbial Biotechnology, Rajiv Gandhi Institute of IT and Biotechnology \\ Bharati Vidyapeeth Deemed University, Katraj, Pune 411 046, Maharashtra, India \\ ${ }^{2}$ National Center of Cell Sciences, University of Pune, Ganeshkhind, Pune 411 007, Maharashtra, India
}

Received 18 May 2010, revised 19 January 2011, accepted 20 January 2011

\begin{abstract}
Marine samples from the Indian Ocean were used to isolate and characterize the organisms with respect to their fatty acid profiles. Six mesophilic isolates (MBRI 6, MBRI 8, MBRI 9, MBRI 10, MBRI 12 and MBRI 13) were obtained from three different water samples. They were i) Gram-negative, ii) catalase positive, iii) produced acid from glucose and maltose, iv) tolerated 5 to $15 \% \mathrm{NaCl} v$ ) except MBRI 9, showed $\mathrm{pH}$ tolerance in the range of 5.0 to 9.0 with optimum $\mathrm{pH} 7.0$ to $8.0 \mathrm{v}$ ) grew well at $30^{\circ} \mathrm{C}$ and were able to grow in the range of 15 to $45^{\circ} \mathrm{C}$. EPA, an essential omega- 3 fatty acid, was produced by these isolates in the range of 12 to $60 \%$ at $30^{\circ} \mathrm{C}$. MBRI 12 was found to be a potential source as it produced $60 \%$ EPA. This isolate was further identified by partial 16S rDNA sequencing and phylogenetic analysis revealed that the strain belonged to Gammaproteobacteria and was closely related to Halomonas bolviensis $(96 \%$ sequence similarity, $570 \mathrm{bp}$ ). Thus a new genus of Halomonas may be included in earlier reported EPA- producing prokaryotic genera affiliated to the Gammaproteobacteria.
\end{abstract}

Ke y w ords: Gammaproteobacteria, Halomonas bolviensis, Alpha-linoleic acid, nutraceuticals, polyunsaturated fatty acid

\section{Introduction}

Long chain polyunsaturated fatty acids (LC-PUFAs) are essential components of membrane lipids of various organisms (Berge and Barnathan, 2005). They are well documented for their beneficial physiological effects in human health including i) lowering of plasma cholesterol and triglycerols ii) prevention of certain cardiovascular diseases (atherosclerosis and thrombosis) and iii) reducing the risk of breast, colon and pancreatic cancer (Robert et al., 2009). Alpha-linoleic acid (ALA), ecosapenthaenoic acid (EPA) and docosahexaenoic acid (DHA) are the major LC-PUFAs of general nutritional importance, suggested by numerous nutritional bodies (Simopoulos et al., 1999). Although the recommended ratio of dietary omega-6 and omega-3 fatty acids is 5:1 (Sargent, 1997), it has shifted heavily towards omega- 6 acids in the current western diet and by some estimate, is up to 30 -fold too high (Simopoulos, 1999). The main reason being an increase in the consumption of vegetable oils rich in omega- 6 fatty acids. Since omega- 6 and omega- 3 fatty acids are not interconvertible in the human body, the ratio of linoleic acid
(LA)/ALA in our diet influences the ratio of omega-6/ omega-3 fatty acids LC-PUFAs. To correct this imbalance, the needed omega-3 LC-PUFAs, can be obtained in our diet from external sources such as fish oil.

The current commercial sources of EPA and DHA are restricted to fish and algal-derived oils. Problems exist with both of these sources. Commercial fish stocks are likely to decline in the future, since the demand for fish oil in the aquaculture industry alone is estimated to exceed the supply by 2010 due to increase in global population (Meyers and Worm, 2003). Besides the concern for the presence of contaminants, such as mercury and polychlorinated biphenyls, in some fish oils, makes it evident that alternative sources of LC-PUFAS must be found (Jacobs et al., 2004). Algal-derived oils require a relatively high investment in technology compared to bacterial fermentation, although bacteria contain a lower proportion of lipid (Nichols et al., 1996). A key advantage of bacterial PUFA production is that only a single PUFA is produced, rather than the complex mixture yielded from fish or algal oils (Russell and Nichols, 1999). Thus bacterial sources of PUFA remove the expense

\footnotetext{
* Corresponding author: R. Bhadekar, phone: 020-24365713; fax: 91-20-24379013; e-mail: neeta.bhadekar@gmail.com
} 
of preparative purification in the production of highpurity PUFA oils. In addition to their potential use as "cell factories" bacteria in particular offer the biotechnological opportunity to study the structure and regulation of the genes and enzymes responsible for PUFA production.

Numerous bacterial species of marine origin producing PUFAs are particularly prevalent in high-pressure, low temperature and deep-sea habitats (Yano et al., 1997). This is an important adaptation for countering the effects of hydrostatic pressure and low temperature on fluidity or phase of membrane lipid (Allen and Bartlett, 2002). Halophilic organisms are also known to be good sources of different bioactive compounds (Margesin and Schinner, 2001). Recently we have reported halotolerant organisms from different food samples (Jadhav et al., 2010a) as well as from wall scrapings of historical building in India (Jadhav et al., 2010b). They were novel owing to their abilities to fix atmospheric nitrogen and produce industrially important enzymes.

Considering the significance of PUFA in human health and limitations in using fish oils, microorganisms prove the best suitable alternative. However use of psychrophilic or piezophilic organisms producing EPA, necessitates the need of low temperature and high pressure facilities (Gentile et al., 2003). Hence use of organisms producing these nutraceuticals at room temperature will be efficient and reasonably priced. The present work was aimed at isolation of marine organisms from the Indian Ocean and characterizing them with respect to their fatty acid profiles. Being mesophilic in nature, high PUFA producing isolates could be conveniently used for pilot scale production and for further scale-up. To our knowledge this is the first report of a high EPA- producing marine isolate from the Indian Ocean.

\section{Experimental}

\section{Material and Methods}

Sampling. Water samples were collected during summer 2008 from different locations in the Indian Ocean (Table I). All chemicals were procured from Himedia and Merck, India. All were of A.R. grade.
Isolation and characterization of microorganisms. $10 \mathrm{ml}$ of each individual sample were inoculated in $100 \mathrm{ml}$ Marine Salt Medium (MSM) (Composition per litre: $81.0 \mathrm{~g} \mathrm{NaCl}, 10.0 \mathrm{~g}$ yeast extract, $9.6 \mathrm{~g}$ $\mathrm{MgSO}_{4}, 7.0 \mathrm{~g} \mathrm{MgCl}_{2}, 5.0 \mathrm{~g}$ protease peptone no 3, $2.0 \mathrm{~g} \mathrm{KCl}, 1.0$ g glucose, $0.36 \mathrm{~g} \mathrm{CaCl}_{2}, 0.06 \mathrm{~g} \mathrm{NaHCO}_{3}$ and $0.026 \mathrm{~g} \mathrm{NaBr}$ with $\mathrm{pH}$ adjusted to $7.0 \pm 0.2$ ) and incubated at $30^{\circ} \mathrm{C}, 120 \mathrm{rpm}$ for $48 \mathrm{hrs}$. After $48 \mathrm{hrs}$, $0.1 \mathrm{ml}$ of each sample was spread on MSM agar plates and incubated for another $48 \mathrm{hrs}$. The isolated colonies were maintained on MSM agar slants.

The isolates were characterized morphologically, physiologically and biochemically. Acid production was studied by using different sugars (glucose, fructose, sucrose, lactose, mannitol and maltose). They were also studied qualitatively for their ability to secrete extracellular enzymes (amylase, catalase, urease, protease, and gelatinase) (Collee et al., 1989).

MSM broth supplemented with various concentrations of $\mathrm{NaCl}$ (ranging from 1-25\%) was used to examine salt-tolerance of the isolates. The cultures were incubated at $30^{\circ} \mathrm{C}, 120 \mathrm{rpm}$ for $24 \mathrm{hrs}$ and cell growth was determined by measuring the absorbance at $660 \mathrm{~nm}$. Temperature tolerance was examined by incubating the cultures at temperatures $15^{\circ} \mathrm{C}, 30^{\circ} \mathrm{C}$ and $45^{\circ} \mathrm{C}$ for $24 \mathrm{hrs}$. Further these isolates were screened for $\mathrm{pH}$ tolerance in MSM broth adjusted to $\mathrm{pH} 5.0-11.0$. The media at different $\mathrm{pH}$ were inoculated with overnight grown inoculum $\left(10^{7} \mathrm{cell} / \mathrm{s} / \mathrm{ml}\right)$. Cell growth was determined by measuring the absorbance at $660 \mathrm{~nm}$.

Preparation of fatty acid methyl esters (FAMES). $10 \%$ inoculum of all the isolates was used to inoculate MSM and incubated at $30^{\circ} \mathrm{C}$ in an orbital shaker (Remi, India) at $120 \mathrm{rpm}$. Cells were harvested after $24 \mathrm{hrs}$ by centrifugation (Plastocraft, India) at 10,000 rpm for 12 mins. Following centrifugation, the supernatant was discarded, the cell pellet resuspended in $1.0 \% \mathrm{NaCl}(\mathrm{w} / \mathrm{v})$, and recentrifuged. Each bacterial culture tube was capped and stored at $4^{\circ} \mathrm{C}$. Cells were reweighed, to which a fresh solution of the transesterification reaction mix (methanolic $\mathrm{HCl}(0.6 \mathrm{~N})$ $4 \mathrm{ml}$ ) was added in the tubes (Carrapiso and Garcia, 2000). The tubes were capped tightly and the solutions were vortexed for $5 \mathrm{~s}$ to $10 \mathrm{~s}$ and heated in an $80^{\circ} \mathrm{C} \pm 2^{\circ} \mathrm{C}$ water bath for $2 \mathrm{hrs}$. The tubes were then cooled quickly in ice.

Table I

Different sampling locations

\begin{tabular}{|c|c|c|c|c|c|c|c|c|c|}
\hline Location & Latitude & Longitude & $\begin{array}{c}\text { Depth } \\
(\mathrm{m})\end{array}$ & $\mathrm{pH}$ & $\begin{array}{c}\text { Tempera- } \\
\text { ture }\left({ }^{\circ} \mathrm{C}\right)\end{array}$ & Salinity & $\begin{array}{c}\text { Conducti- } \\
\text { vity }(\mathrm{ms})\end{array}$ & $\begin{array}{c}\text { D.O. } \\
(\mathrm{mg} / \mathrm{l})\end{array}$ & \multicolumn{1}{|c|}{ Isolates } \\
\hline 6NT/LT/BOT & $18^{\circ} 48^{\prime \prime} 52^{\prime \prime} \mathrm{N}$ & $72^{\circ} 46^{\prime} 30^{\prime \prime}$ & 13 & 8.02 & 30.4 & 71.61 & 974.7 & 3.98 & MBRI 9, MBRI 10 and MBRI 12 \\
\hline 2NT/LT/BOT & $15^{\circ} 33.01 " 6 ” \mathrm{~N}$ & $73^{\circ} 56.58^{\prime \prime}$ & 9.5 & 7.62 & 31.8 & 27.05 & 412.4 & 4.72 & MBRI 8 \\
\hline 2ST/LT/BOT & $15^{\circ} 33.01 " 6 ” \mathrm{~N}$ & $73^{\circ} 56.58^{\prime} \mathrm{E}$ & 11 & 7.62 & 31.8 & 27.05 & 412.4 & 4.72 & MBRI 6 and MBRI 13 \\
\hline
\end{tabular}


The resultant FAMES were extracted twice by adding 2 volumes of hexane and then 1 volume of hexane by centrifugation at $5000 \mathrm{rpm}$ for 15 mins. The upper phase of hexane layer was separated and stored for gas chromatography analysis.

Gas chromatography analysis of bacterial extracts. Analyses of the FAMES were performed with a Chemito GC 1000 equipped with a $50 \mathrm{~m} \times 0.25 \mathrm{~mm}$ internal diameter cross-linked methyl silicone fusedsilica CP - SIL 88 capillary column and flame ionization detector. Samples were injected at $100^{\circ} \mathrm{C}$ in the split mode. After 5 mins the oven was temperature-programmed from $100^{\circ} \mathrm{C}$ to $198^{\circ} \mathrm{C}$ at the rate of $1.5^{\circ} \mathrm{C} \mathrm{min}-1$ and hold for 9 mins. Nitrogen was used as a carrier gas, and the injector and detector were maintained at 225 and $250^{\circ} \mathrm{C}$ respectively. Peak areas were quantified using chromatography software (IRIS 32, India).

16S rDNA sequencing. The isolate producing high amount of PUFA was used for identification by $16 \mathrm{~S}$ rDNA sequencing. The genomic DNA was isolated as described by Ausubel et al. (1987). The PCR assay was performed using Applied Biosystems, model 9800 with $1.5 \mu \mathrm{l}$ of DNA extract in a total volume of $25 \mu$ l. The PCR master mixture contained $2.5 \mu \mathrm{l}$ of 10X PCR reaction buffer (with $1.5 \mathrm{M} \mathrm{MgCl}_{2}$ ), $2.5 \mu \mathrm{l}$ of $2 \mathrm{mM}$ dNTPs, $1.25 \mu \mathrm{l}$ of $10 \mathrm{pm} / \mu \mathrm{l}$ of each oligonucleotide primers $27 \mathrm{f}$ ( $5^{\prime} \mathrm{CCAGAGTTTGATCGT}$ GGCTCAG3'), 1488r(5'CGGTTACCTTGTTACGA CTTCACC 3'), $0.24 \mu 1$ of Taq DNA polymerase and $15.76 \mu 1$ of glass distilled PCR water.

Initially denaturation accomplished at $94^{\circ} \mathrm{C}$ for $3 \mathrm{~min}$. Thirty-five cycles of amplification consisted of denaturation at $94^{\circ} \mathrm{C}$ for $1 \mathrm{~min}$, annealing at $55^{\circ} \mathrm{C}$ for $1 \mathrm{~min}$ and extension at $72^{\circ} \mathrm{C}$ for $1 \mathrm{~min}$. A final extension phase at $72^{\circ} \mathrm{C}$ for $10 \mathrm{~min}$ was performed. The PCR product was purified by PEG-NaCl method. The sample was mixed with 0.6 times volume PEG-NaCl [20\% PEG (MW 6000), $2.5 \mathrm{M} \mathrm{NaCl}]$ and incubated for $40 \mathrm{~min}$ at $37^{\circ} \mathrm{C}$. The precipitate was collected by centrifugation at $3,800 \mathrm{rpm}$ for $28 \mathrm{~min}$. The pellet was washed with $70 \%$ ethanol, air dried and sequenced using 96 well sequencing plate as per manufacturer's instructions.

The thermocycling for the sequencing reactions was performed with a 9800 PCR model (Applied Biosystems). It began with an initial denaturation at $94^{\circ} \mathrm{C}$ for $2 \mathrm{~min}$, followed by 35 cycles of PCR consisting of denaturation at $94^{\circ} \mathrm{C}$ for $10 \mathrm{sec}$, annealing at $50^{\circ} \mathrm{C}$ for $10 \mathrm{sec}$ and extension at $68^{\circ} \mathrm{C}$ for $4 \mathrm{~min}$.

The samples were purified using standard protocols described by Applied Biosystems, Foster City, USA. To this, $10 \mu \mathrm{l}$ of Hi-Di formamide was added and vortexed briefly. The DNA was denatured by incubating at $95^{\circ} \mathrm{C}$ for $3 \mathrm{~min}$, kept on ice for $5-10 \mathrm{~min}$ and was sequenced in a 3730 DNA analyzer (Applied Biosystems) following manufacturer's instructions.
Nucleotide sequence accession number. The partial 16S rDNA sequence generated in this study was deposited in Gen Bank + EMBL+DDBJ + PDB under the accession number GU593323. Sequence was compared with the compilation of 16S rDNA genes available in the Gen Bank + EMBL+DDBJ+PDB library by BLASTN 2.2.17 searching.

\section{Results and Discussion}

Isolation and characterization. Total six bacterial isolates were isolated from the three samples of Indian Ocean (Table I). The isolates were grown and maintained on MSM. They were named as MBRI 6, MBRI 8, MBRI 9, MBRI 10, MBRI 12 and MBRI 13. All 6 MBRI isolates were characterized morphologically, biochemically and physiologically. They i) were Gramnegative ii) produced catalase, iii) produced acid from glucose and maltose, iv) tolerated 5 to $15 \%$ of salt, v) except MBRI 9, showed $\mathrm{pH}$ tolerance in the range of $5.0-9.0$ with optimum $\mathrm{pH}$ of $7.0-8.0$, vi) grew well at $30^{\circ} \mathrm{C}$ and $\mathrm{v}$ ) were able to grow in the range of 15 to $45^{\circ} \mathrm{C}$. MBRI 6, MBRI 8, MBRI 9 and MBRI 10 produced acid from fructose while MBRI 6, MBRI 8 and MBRI 13 used lactose. Only MBRI 11 was able to utilize sucrose as carbon source. MBRI 10 and MBRI 12 could grow on citrate as carbon source. MBRI 9 tolerated a wide $\mathrm{pH}$ range of 6.0-9.0.

Fatty acid profile. All six isolates were analysed for their fatty acids profiles (Table II). The results indicated that total saturated fatty acids, monounsaturated fatty acids and polyunsaturated fatty acids were in the range of 21 to $100 \%, 11$ to $30 \%$ and 1 to $62 \%$ respectively. Interestingly, MBRI 10 did not show presence of unsaturated fatty acids. Linoleic acid was the only omega- 6 fatty acid detected in MBRI 8, MBRI 9 and MBRI 12. It was detected in the range of 1 to $6 \%$, while omega- 3 fatty acids were ALA and EPA ( 0.5 to $16 \%$ and 12.0 to $60 \%$, respectively). Arachinoidic acid and docosahexanoic acid were not detected in any of the isolates. Trans-fatty acids were also not detected in these isolates. So far, EPA has mainly been reported to occur in eukaryotes and some peizophilic or psychrophilic microorganisms (Freese et al., 2009). Bacteria are known to alter the composition of their phospholipid fatty acids side-chains in order to maintain appropriate membrane organization and function (Suutari and Laakso, 1994). At low temperatures or high pressures, the content of unsaturated fatty acids often increases with a concomitant decline in saturated fatty acids (Allen et al., 1999). Polyunsaturated fatty acids (PUFAs), such as EPA and DHA, are particularly effective in the adjustment of membrane fluidity due to their low melting points (Hazel, 1995). Hence several EPA producing marine organisms isolated 
Table II

Fatty acid profile of MBRI isolates

\begin{tabular}{|c|r|r|r|r|r|r|}
\hline Fatty acids & MBRI 6 & MBRI 8 & MBRI 9 & MBRI 10 & MBRI 12 & MBRI 13 \\
\hline C 4:0 & 0.2 & 7.7 & 11.6 & 21.9 & 6.8 & 19.3 \\
\hline C 6:0 & 0.4 & 2.2 & 2.7 & 8.4 & 2.0 & 7.3 \\
\hline C 8:0 & 2.2 & 4.5 & 8.3 & 2.5 & N.D. & 2.4 \\
\hline C 10:0 & 0.5 & 0.7 & 3.8 & 5 & 1.2 & N.D. \\
\hline C 11:0 & 0.7 & 0.8 & 1.2 & 6.1 & 1.4 & 1.1 \\
\hline C 12:0 & 0.8 & 1.0 & N.D. & N.D. & N.D. & 0.8 \\
\hline C 13:0 & N.D. & N.D. & 1.4 & N.D. & N.D. & N.D. \\
\hline C 14:0 & 18.1 & 34.3 & 8.7 & 14.1 & 1.7 & 4.1 \\
\hline C 15:0 & N.D. & N.D. & N.D. & N.D. & N.D. & 1.9 \\
\hline C 16:0 & 25.1 & 19.7 & 22.0 & 42.1 & 8.5 & 8.1 \\
\hline C 17:0 & N.D. & 0.9 & 0.9 & N.D. & N.D. & 4.8 \\
\hline C 18:0 & 7.2 & 11.7 & 0.8 & N.D. & N.D. & 2.5 \\
\hline C 16:1 & 55.3 & 83.5 & 61.4 & 100 & 21.6 & 52.3 \\
\hline C 18:1 & 1.6 & 2.7 & 25.7 & N.D. & 12.1 & 10.7 \\
\hline C 22:1 & 6.9 & 0.9 & 2.7 & N.D. & 4.7 & 2.5 \\
\hline C 17:1 & 0.6 & N.D. & N.D. & N.D. & N.D. & N.D. \\
\hline Total Saturated Fatty acids & 2.3 & 11.7 & 1.1 & N.D. & N.D. & N.D. \\
\hline C 18:2 n6t & 11.4 & 15.3 & 29.5 & N.D. & 16.8 & 13.2 \\
\hline C 18:2 n6c & N.D. & 1.1 & 5.9 & N.D. & 1.5 & N.D. \\
\hline C 18:3 n6 & 4.7 & N.D. & 0.8 & N.D. & N.D. & N.D. \\
\hline C 20:5 n3 & 15.9 & N.D. & 2.5 & N.D. & 0.7 & N.D. \\
\hline Total Unsaturated Fatty Acids & 12.8 & N.D. & N.D. & N.D. & 59.5 & 34.4 \\
\hline & 33.8 & 1.1 & 9.2 & N.D. & 61.7 & 34.4 \\
\hline Total Polyunsaturated Fatty Acids & & & &
\end{tabular}

N.D. - Not detected

were psychophilic and peizophilic from polar regions and deep sea, as mentioned earlier. However the recent isolation of mesophilic EPA-producing Shewanella species from a temperate estuary (Skerratt et al., 2002) and from shallow seawater samples (Frolova et al., 2005; Freese et al., 2008) suggested that EPA may not be restricted to psychrophiles and piezophiles.

Figure 1 shows the comparison of \% EPA produced by our isolates with that of microalgae and mesophilic bacterial cultures. Vazhappilly and Chen (1998) have reported upto $34.2 \%$ EPA in various microalgae at $25^{\circ} \mathrm{C}$. However recovery of EPA from these sources is difficult along with poor yields. Freese et al. (2009) have documented up to 1.2\% EPA in various organisms at $30^{\circ} \mathrm{C}$ (Fig. 1). Different sp. of Shewanella were reported to produce EPA up to $6.5 \%$ at $28^{\circ} \mathrm{C}$ (Ivanova et al., 2003; Ivanova et al., 2004; Hirota et al., 2005), probably indicating that temperature sensitive enzymes were involved in biosynthesis. Thus our isolates appear novel owing to their ability to produce high EPA at $30^{\circ} \mathrm{C}$. Also these studies contradict the notion that only barophilic or cold-adapted species are able to produce significant levels of PUFAs such as EPA.

Oleaginous fungi are also known to store large amounts of lipid, mainly triglycerols, and Mortierella spp. are noteworthy for the n-3 and n-6 PUFA contents of their stored lipid. Typically up to $40 \%$ of the fungal dry weight may be triacylglycerol in which the acyl chains are up to $15 \%$ EPA or $55 \%$ AA (Singh and Ward, 1997). Our results are comparable to these observations besides the advantage of rapid cultivation and easy recovery.

Branched chain fatty acids (BCFAs) have repeatedly been reported to promote cold adaptations (Chattopadhyay and Jagannadham, 2001). Our results showing comparatively low levels (1 to 34\%) of BCFAs in all the isolates except MBRI 10 support these observations. However in some other bacteria no clear changes in BCFAs with varying growth temperature were observed (Nichols et al., 2002).

Phylogeny. MBRI 12, the highest EPA producing isolate was identified using partial $16 \mathrm{~S}$ rDNA sequencing. The sequence was deposited in EMBL + Genbank under accession number GU593323. BLAST analysis of partial 16S rDNA sequence revealed that the strain belonged to Gammaproteobacteria and was closely related to Halomonas bolviensis (96\% sequence similarity, $570 \mathrm{bp}$ ). All so far known EPA-producing prokaryotes affiliate with only a few genera within two bacterial phyla: The Gammaproteobacteria (e.g. genera Shewanella, Moritella, Colwellia, Alteromonas, 


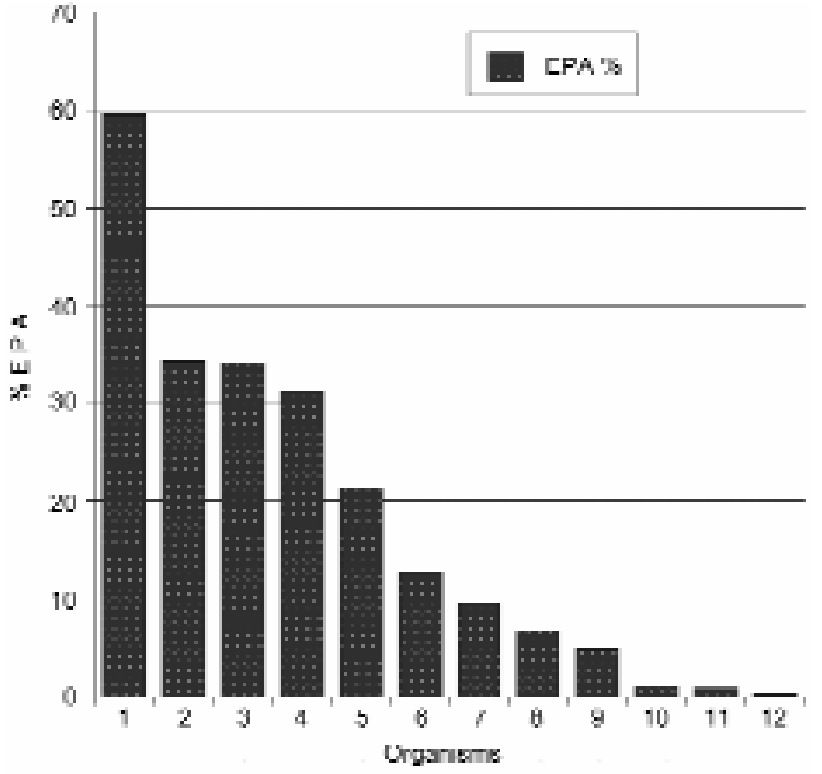

Fig. 1. Comparison of \% EPA produced by MBRI isolates (this work) with other mesophilic marine bacteria and microalgae. 1. MBRI 12 ; 2. MBRI 13; 3. Monodus subterraneus UTEX 151, 4. Chlorella minutissima UTEX 2341, 5. Phaeodactylum tricornutum UTEX 642 (Vazhappilly and Chen, 1998); 6. MBRI 6; 7. Shewanella pneumatophori (Hirota et al., 2005); 8. Shewanella waksmanii (Ivanova et al., 2003); 9. Shewanella pacifica (Ivanova et al., 2004); 10. Photobacterium sp. SAMA2, 11. Vibrio sp. NB73, 12. Shewanella $\mathrm{sp}$. NB72 (Freese et al., 2009).

and Photobacterium) and the Bacteroidetes (e.g Flexibacter and Psychroserpens). Therefore, EPA may be a potentially useful marker for these genera in environmental microbial communities (Freese et al., 2009). Our results suggest that a new genus of Halomonas may be added to earlier reported EPA producing prokaryotic genera belonging to Gammaproteobacteria.

Conclusions. 1. The occurrence of high levels of EPA in MBRI isolates (present work) with MBRI 12 being highest producer of EPA which could be commercially exploited. 2. This is probably the first report of Halomonas sp. producing EPA at $30^{\circ} \mathrm{C}$ in the presence of high salt-concentration.

\section{Acknowledgements}

This work is financially supported by the Department of Biotechnology, New Delhi, Government of India. We are thankful to Honorable Dr. Shivajirao Kadam, V.C., Bharati Vidyapeeth Deemed University and Dr. R.M. Kothari, Principal, Rajiv Gandhi Institute of IT and Biotechnology, (BVDU) for providing facilities to undertake this work. We are also thankful to Dr. D.P. Nerkar and Ms. V. V. Jadhav for their assistance.

\section{Literature}

Allen E.E. and D.H. Bartlett. 2002. Structure and regulation of the omega-3 polyunsaturated fatty acid synthase genes from the deep-sea bacterium Photobacterium profundum strain SS9. Microbiology 148: 1903-1913.
Allen E.E. and D.H. Bartlett. 1999. Monounsaturated but not polyunsaturated fatty acids are required for growth of the deep-sea bacterium Photobacterium profundum SS9 at high pressure and low temperature. Appl. Environ. Microbiol. 65: 1710-1720.

Ausubel F.M., R. Rrent, R.E. Kingston, D.D. Moore, J.G. Seidman, J.A. Smith and K. Struhl. 1987. Current Protocols in Molecular Biology. Wiley, New York.

Berge J.P. and G. Barnathan. 2005. Fatty acids from lipids of marine organisms: molecular biodiversity, role as biomarkers, biologically active compounds and economical aspects. $A d v$. Biochem. Eng. Biotechnol. 96: 49-125.

Carrapiso A.I., and C. Garcia. 2000. Development in lipid analysis: some new extraction techniques and in situ transesterification. Lipids 5(11): 1167-77.

Chattopadhyay M.K. and M.V. Jagannadham. 2001. Maintenance of membrane fluidity I Antarctic bacteria. Polar. Biol. 24: 386-388.

Collee J.G., J.P. Duguid, A.G. Fraser and B.P. Marmion. 1989. Practical Medical Microbiology. Churchill Livingstone, Medical Division of Longman Group UK Ltd., New York.

Freese E., J. Koster and J. Rullkoter. 2008. Origin and composition of organic matter in tidal flat sediments from the German Wadden Sea. Org. Geochem. 39: 820-829.

Freese E., H. Rutters, J. Koster, J. Rullkoter and H. Sass. 2009. Gammaproteobacteria as a possible source of ecosapentanoic acid in anoxic intertidal sediments. Aqu. Microbiol. 57: 444-454

Frolova G.M., K.G. Pavel, A.A. Shparteeva, O.I. Nedashkovskaya, N.m. Gorhkova, E.P. Ivanova, and V.V. Mikhail. 2005. Lipid composition of novel Shewanella species isolated from far eastern seas. Microbiology 74: 664-669.

Gentile G., V. Bonasera, C. Amico, L. Giuliano and M.M. Yakimov. 2003. Shewanella sp. GA-22, a psychrophilic hydrocarbonoclastic antarctic bacterium producing polyunsaturated fatty acids. J. Appl. Microbiol. 95: 1124-1133

Hazel J.R. 1995. Thermal adaptation in biological membranes: is homeoviscous adaptation the explanation? Annu. Rev. Physiol. 57: $19-42$

Hirota K.Y. Nodasaka, Y. Orikasa, H. Okuyama and I. Yumoto. 2005. Shewanella pneumatophori sp. nov., an eicosapentaenoic acid producing marine bacterium isolated from the intestines of Pacific mackerel (Pneumatophorus japonicus). Int. J. Syst. Evol. Microbiol. 55: 2355-2359

Ivanova E.P., N.M. Gorshkova, J.P. Bowman, A.M. Lysenko, N.V. Zhukova, A.F. Sergeev, V.V. Mikhailov and D.V.N. 2004 Shewanella pacifica sp. nov., a polyunsaturated fatty acid-producing bacterium isolated from sea water. Int. J. Syst. Evol. Microbiol. 54: 1083-1087.

Ivanova E.P., O.I. Nedashkovskaya, N.V. Zhukova, D.V. Nicolau, R. Christen and V.V. Mikhailov. 2003. Shewanella waksmanii sp. nov., isolated from a sipuncula (Phascolosoma japonicum) Int. J. Syst. Evol. Microbiol. 53: 1471-1477.

Jacobs M.N., A. Covaci, A. Gheorghe and P. Schepens. 2004. Time trend investigation of PCBs, OCPs, and PBDEs in n-3 polyunsaturated fatty acid-rich dietary fish oil \& vegetable oil supplement; Nutritional relevance for human essential n-3 fatty acid requirement. J. Agri. Food. Chem. 52: 1780-1788.

Jadhav G.G., D.S. Salunkhe, D.P. Nerkar and R.K. Bhadekar. 2010a. Isolation and characterization of salt-tolerant nitrogenfixing microorganisms from food. Eur. J. Biosci. 4: 33-40

Jadhav G.G., D.S. Salunkhe, D.P. Nerkar and R.K. Bhadekar. 2010b. Novel Staphylococcus sp. isolated from wall scrapings of a historical building in India. Ann. Microbiol. 60: 197-201. 
Margesin R. and F. Schinner. 2001. Potential of halotolerant and halophilic microorganisms for biotechnology. Extremophiles 5(2): 73-83

Meyers R.A. and B. Worm. 2003. Rapid worldwide depletion of predatory fish communities. Nature 432: 280-283.

Nichols D.S., P. Hart, P.D. Nichols and T.A. McMeekin. 1996 Enrichment of the rotifer Brachinous plicatilis fed an Antarctic bacterium containing polyunsaturated fatty acid. Aquaculture 147: $115-125$.

Nichols D.S., K.A. Presser, J. Olley, T. Ross and T.A. McMeeekin. 2002. Variation of branched-chain fatty acids marks the normal physiological range for growth in Listeria monocytogenes. Appl. Environ. Microbiol. 68: 2809-2813

Robert S.S., J. R. Petrie, X. Zhou, M. P. Mansour, S.I. Blackburn, A.G. Green, S.P. Singh and P.D. Nichols. 2009 Isolation and characterization of a $\Delta 5$-fatty acids elongase from the marine microalgae Pavlova salina. Mar. Biotechnol. 11: 410-418. Russell N.J., and D.S. Nichols. 1999. Polyunsaturated fatty acids in marine bacteria - a dogma rewritten. Microbiology 145: 767-779. Sargent J.R. 1997. Fish oils and human diet. Br. J. Nutr. 78 Suppl. 1, 5-13.
Simopoulos A.P., A. Leaf and N., Jr Salem. 1999. Workshop on the essentiality of and recommended dietary intakes for omega- 6 and omega-3 fatty acids. Food. Aust. 51: 332-333.

Simopoulos A.P. 1999. Essential fatty acids in health and chronic disease. Am. J. Clin. Nutr. 70(3): 560S-569S.

Singh A. and O.P. Ward. 1997. Microbial production of docosahexaenoic acid (DHA, 22:6) Adv. Appl. Microbiol. 45: 271-312.

Skerratt J.H., J.P. Bowman and P.D. Nicholas. 2002. Shewanella olleyana sp. nov., a marine species isolated from a temperate estuary which produces high levels of polyunsaturated fatty acids Int. J. Syst. Evol. Microbiol. 52: 2101-2106.

Suutari M. and S. Laakso. 1994. Microbial fatty-acids and thermal adaptation. Crit. Rev. Microbiol. 20: 285-328

Vazhappilly R and F. Chen. 1998. Eicosapentaenoic acid and docosahexaenoic acid production potential of microalgae and their heterotrophic growth. J. Am. Oil Chem. Soc. 75(3): 393-397

Yano Y., A. Nakayama and K. Yoshida. 1997. Distribution of polyunsaturated fatty acids in bacteria present in intestines of deepsea fish and shallow-sea poikilothermic animals. Appl. Environ. Microbiol. 63: 2572-2577. 